\title{
Fotografia, história e cultura fotográfica: aproximações
}

IVO CANABARRO*

\begin{abstract}
Resumo: Neste artigo discute-se a importância da fotografia para a historiografia, observando-se que o uso desta fonte visual ainda é muito recente e restrito. Os historiadores, apesar de admitir a variada gama de fontes documentais, preferem as fontes escritas em detrimento do visual e da oral. Nesta perspectiva, procura-se refletir a centralidade da imagem na contemporaneidade e sua contribuição para historiadores pensar a dimensão visual da sociedade.

Abstract: It is considered in this article the relevance of photography to historiography, observing that the use of this visual resource is still too recent and limited. Historians, in spite of accepting the diverse range of document sources, prefer written sources in spite of visual or oral ones. In this sense, it is shown the central role that image plays in contemporary times and its contribution to lead historians to consider the visual dimension of society.
\end{abstract}

Palavras-chave: Fotografia. História. Cultura fotográfica.

Key words: Photography. History. Photographic culture.

Na contemporaneidade, as imagens aparecem nos distintos meios de circulação da cultura. Elas representam pequenos fragmentos que indicam os diferentes modos de vida dos atores sociais, a forma como compreendem o mundo, suas representações, o imaginário e as mesmo cenas muito próximas de seu cotidiano. As imagens parecem mais sedutoras do que a realidade, permitem ao observador fazer viagens por lugares nunca dantes imagináveis e descobrem o próprio mundo. Dentre a diversidade de imagens, escolhe-se a fotografia para a discussão sobre o conhecimento, pois

Professor da UNIJUI, doutor em História Social pela Universidade Federal Fluminense e Universidade de Paris III. E.mail: icanabarro@yahoo.com.br

Estudos Ibero-Americanos. PUCRS, v. XXXI, n. 2, p. 23-39, dezembro 2005 
se compreende como uma fonte de valor inestimável na construção de interpretações sobre a história.

A fotografia é um produto social e cabe ao historiador perceber como as imagens constituem uma certa maneira discursiva de colocar em cena questões e fragmentos da história, percebidos no encaixe de uns documentos com os outros na tentativa de se entender sua forma evolutiva e, ao mesmo tempo, descontinua. Desta forma, a história aproxima-se do presente, com a fotografia, permitindo entender a história oficial, a secreta, a individual e a coletiva. A história do sentido das fotografias, a cada período, sofre renovação de suas funções: a fotografia social, a popular, a mediática dentre outras. As imagens fotográficas são todas plausíveis à ação dos campos, das influências, das filiações, das referências, das determinações sociais e dos códigos de leitura, não estando atreladas ao determinismo tecnológico, pois, antes de tudo, são produtos sociais. ${ }^{1}$

Os trabalhos sobre fotografia no Brasil são muito recentes, embora a prática fotográfica tenha iniciado há mais de cento e cinqüenta anos. Este longo percurso da fotografia repercute em uma grande produção quantitativa e qualitativa. Os inúmeros acervos de imagens espalhados por todo o Brasil são capazes de revelar situações inéditas da cultura brasileira. Pode-se afirmar que parte significativa da história do Brasil ainda permanece revelada apenas na bidimensionalidade das fotografias. Alguns historiadores afirmam que, em termos de utilização da fotografia, há praticamente, tudo para fazer, visto ter muitas imagens, porém poucos trabalhos.

A constatação de que existem vários acervos fotográficos no Brasil contribui para a importância de se utilizar a fotografia para a construção do conhecimento. Os acervos constituem-se em fontes, de certa forma, privilegiadas, por comportarem informações que nem sempre são encontradas na documentação escrita. As fontes imagéticas permitem ir muito além das meras descrições, porque trazem expressões de realidades vividas em outros tempos. Da mesma forma, devido à diversidade de informações que as fotografias apresentam, por registrarem distintas situações de vivência dos atores individuais e coletivos, possibilitam o entendimento das diferenças sociais dos grupos, revelando questões que

1 A fotografia como produto social é defendida pelos historiadores que trabalham com a noção de história social da fotografia, tendência esta com muitos adeptos na França, liderada por Michel Frizot expressa na obra que organiza. FRIZOT, Michel (Org.). Nouvelle histoire de la photographie. Paris: Adan Biro / Larousse, 2001. 
dizem respeito à sua atuação em um determinado contexto histórico.

A fotografia, como fonte de pesquisa, propicia ao historiador acrescentar novas e diferentes interpretações da história social. A partir da leitura dos elementos que a compõem, compreendem-se em detalhes o caráter simbólico, expresso por diversos sistemas de atitudes relacionadas às representações sociais. As imagens fotográficas revelam alguns elementos importantes para o conhecimento da memória coletiva. Neste sentido, Le Goff ${ }^{2}$ observa que a fotografia revoluciona a memória, multiplicando-a e democratizando-a, dando uma precisão e uma verdade que permite guardar a memória do tempo e da evolução da sociedade.

As imagens fotográficas possibilitam ampliar a visão do historiador, colocam em cena atores sociais em diferentes situações de atuação e permitem que se conheçam os cenários em que as atividades cotidianas desenvolvem-se, como também, a diversidade das articulações e das vivências dos atores sociais que atuaram em um determinado contexto sócio-cultural. Poderá, sobretudo servir como suporte para a memória coletiva desses atores, na medida que registram cenas de um tempo continuum que foram perenizadas no ato fotográfico, podendo ser transportadas para outras temporalidades, mediante uma mistura de passado-presente.

\section{Os historiadores e os usos da fotografia}

A utilização de fotografias pelos historiadores é uma prática muito recente e, por conseguinte, restrita. Chega-se a inferir que estes não gostam de imagens, pois preferem deter-se nas fontes escritas. Entretanto, não significa reduzir o valor do documento escrito, mas são consideradas as possibilidades de conhecimento de outras dimensões da vivência dos atores sociais por intermédio das fotografias. Salienta-se que as fotografias não devem ser utilizadas simplesmente como uma ilustração do texto verbal, mas como fontes de pesquisas, visto que os elementos que a compõem são recortados de determinados contextos sociais. Embora a fotografia seja uma representação visual, todos os elementos ou pessoas que estiveram por um momento em frente da câmera fotográfica são plausíveis de serem alocados em um determinado tempo e espaço. Esta possibilidade atesta o caráter histórico da fotografia.

2 LE GOFF, Jacques. História e memória. Campinas: Unicamp, 1996. 
No conjunto de imagens que traduzem o mundo, a fotografia pode servir como uma alternativa a mais de leitura da realidade. Enquanto produto cultural, é uma construção feita por um sujeito mediador, o fotógrafo, que seleciona pessoas e elementos e os enquadra na bidimensionalidade de um espaço a ser recortado. Entre este sujeito e o retratado está a tecnologia, que permite a fixação da cena escolhida. Visto a fotografia ser um produto cultural, a sua construção faz parte de um determinado contexto histórico, que influencia na construção do olhar do fotógrafo, nas representações sociais impressas e no equipamento tecnológico empregado para a tomada da imagem.

O historiador precisa situar a fotografia em um determinado tempo e espaço e perceber as suas alterações e do contexto. O oficio do historiador consiste na realização da crítica interna e externa do documento e, neste sentido, alguns métodos de análise permitem-lhe a leitura dos documentos visuais. O historiador da fotografia Michel Frizot ${ }^{3}$ observa que se a fotografia é um documento, ele é histórico por natureza, pois o tempo que retrata e as particularidades do instante são fragmentos da história geral.

Os historiadores que trabalham com fotografias como documento discutem as fontes visuais, situando-as em um determinado momento em que a historiografia ocidental começa a ser construída por diferentes olhares, abordagens e objetos, ampliando a noção de fonte documental. Com influência da Escola dos Annales, ${ }^{4}$ a partir dos anos trinta do século XX, a noção de fonte documental é ampliada e a imagem também passa a constituir-se como um resíduo do passado, um traço capaz de atestar situações de vivência. Nesta perspectiva, Chartier ${ }^{5}$ observa que a imagem passou a ser apreendida como documento histórico, ou seja, as propriedades técnicas, estilísticas e iconográficas ligam-se a um modo particular de percepção e uma maneira de ver, moldada em toda a experiência social.

A utilização das fontes visuais para a construção do conhecimento na história é ainda muito restrita e de certa forma proble-

3 FRIZOT, Michel (Org.). Nouvelle histoire de la photographie. Paris: Adan Biro / Larousse, 2001.

4 Um breve retrospecto sobre a Escola dos Annales pode ser constatado em: BURKE, Peter. A Escola dos Annales (1929-1989). São Paulo: UNESP, 1991.

5 CHARTIER, Roger. Verbete Imagens. In: BURGUIÈRE, André. Dicionário das ciências históricas. Rio de Janeiro: Imago, 1993, p. 407. 
mática. Sobre esta questão, Meneses ${ }^{6}$ comenta que é possível pensar em uma História Visual, produzida a partir de documentos visuais para tentar examinar a dimensão visual da sociedade. $\mathrm{O}$ mesmo autor pondera que o visual refere-se à sociedade e não às fontes para o seu conhecimento; neste sentido, o objeto é sempre a sociedade, cabendo ao historiador trabalhar com os problemas históricos, buscando a solução por intermédio de fontes visuais, juntamente com outras fontes documentais.

A fotografia como uma fonte visual começa a ser trabalhada com mais ênfase na França, a partir da terceira geração dos Annales. Le Goff e Nora ${ }^{7}$ avançam nas discussões sobre os novos problemas, as novas abordagens e os novos objetos, atribuindo à fotografia o caráter de fonte documental e resgatando sua importância para o trabalho de reconstrução do passado. Ao mesmo tempo, dá credibilidade às pesquisas realizadas sobre a história social da fotografia.

Para Le Goff, ${ }^{8}$ a fotografia está entre os grandes documentos para se fazer história, por consistir de provas de que algo aconteceu. O autor observa que a fotografia permite conhecer a riqueza da vida, mesmo sendo realista, porque o próprio realismo é também uma criação. A fotografia representa uma inegável expressão do indivíduo, da face, do retrato e, também, expressão da vida cotidiana do camponês. A imagem mostra toda a riqueza do simples ato de ver, por ser um texto visual que exprime a plenitude do humanismo. $\mathrm{O}$ autor finaliza salientando que se existem provas concretas do passado e a fotografia é uma delas.

O historiador Pierre Nora ${ }^{9}$ observa que, a partir dos anos 70 do século XX, o texto visual, principalmente a fotografia, passa a fazer parte da escrita da história. O autor salienta que o alargamento da história, propiciado pela "nouvelle histoire", influencia a valorização do arquivo visual. Paralelo a isso, a noção de testemunha passa a ser entendida como noção de traço e o não escrito começa a dilatar o domínio da história. Nora entende a fotografia como um instantâneo extraído do movimento permanente, uma

6 MENESES, Ulpiano T. Bezerra. Fontes visuais, cultura visual, história visual. Balanço provisório, propostas cautelares. In. Revista Brasileira de História, São Paulo, ANPUH / Humanitas Publicações, v. 23, n. 45, p. 11-36, 2003.

7 LE GOFF, Jacques; NORA, Pierre. História - novos problemas, novas abordagens, novos objetos. Rio de Janeiro: Francisco Alves, 1995.

8 LE GOFF, Jacques. Mirages de l'histoire. In: La Recherche Photographique, Paris, Paris Audiovisuel, n. 18, 1995.

9 NORA, Pierre. Historiens, photographes: voir et devoir. In: CAUJOLLES, Cristian (Dir.). Éthique, esthétique, politique. Arles: Actes Sud, 1997. 
mostra representativa de uma realidade distante, um analogon do que foi o passado e uma relação de descontinuidade decorrente de uma mistura de distância e de aproximação. Deste modo, cabe ao historiador perceber o valor de diferença do que se apresenta e o movimento que continua a existir. Naturalmente, esse é um longo trabalho que exige muita erudição na restituição de um objeto histórico.

Apesar do entusiasmo de historiadores conceituados, tais como Le Goff e Nora, pouco foi feito relativo à utilização das fotografias para a construção do conhecimento histórico. Em recente texto publicado na Revista Études photographiques ${ }^{10}$ com o sugestivo título "L'histoire par la photographie", os autores observam que se tem realizado muitos trabalhos sobre a história $d a$ fotografia, mas pouco se discutiu sobre a história pela fotografia, devido aos raros pesquisadores que se dedicam à análise de arquivos fotográficos. Esta discussão também está presente em algumas obras de historiadores brasileiros, os quais procuram salientar esta diferenciação e/ou aproximação entre a história da fotografia e a história pela fotografia.

A historiadora Maria Inez Turazzi ${ }^{11}$ observa que, do ponto de vista historiográfico, a fotografia enseja uma multiplicidade de temas pouco explorados. Salienta que, tanto no Brasil como no exterior, a maioria das coletâneas de fotos relaciona-se a algum tema específico, predominando os trabalhos em que a fotografia é o próprio objeto de pesquisa. A autora prossegue a análise, enfatizando que a escassez de estudos sobre a história da fotografia no Brasil dificulta o desenvolvimento de novos trabalhos historiográficos. Neste sentido, Turazzi argumenta que a falta de pesquisas nesta área específica dificulta a tarefa do historiador em realizar a contextualização das fotografias, e em estabelecer as relações com outros aspectos da vida social. As observações de Turazzi, feitas no início da década de 1990, referiam-se a um conjunto de obras disponíveis no período, contudo, este quadro tende a alterarse com as recentes publicações tanto no Brasil quanto no exterior.

Outros autores brasileiros que trabalham com fotografias apontam as limitações e as dificuldades neste domínio específico. Para Kossoy, ${ }^{12}$ é necessário o estabelecimento de algumas diferenças teóricas, relativas aos objetos de investigação da história da

10 Revista Études photographiques, Société Française de Photographie, Paris, n. 10, nov. 2001.

11 TURAZZI, Maria Inez. Poses e trejeitos - a fotografia e as exposições na era do espetáculo. Rio de Janeiro: Rocco, 1995, p. 19.

12 KOSSOY, Boris. Fotografia e história. São Paulo: Ática, 1989, p. 35-37. 
fotografia como na história através da fotografia. No primeiro caso, o autor salienta que é um estudo sistemático da fotografia como um meio de comunicação e de expressão em seu processo histórico. Afirma que é importante conhecer os artefatos representativos dos diferentes períodos, a tecnologia utilizada e os estilos e as tendências de representação vigentes em um certo período histórico. Considera ainda fundamentais as circunstâncias ligadas ao processo que originou a imagem, como também o seu uso enquanto testemunho visual, em suas diferentes aplicabilidades ao longo de sua história.

No segundo caso, Kossoy observa que a história pela fotografia é o emprego da fotografia do passado nos diferentes gêneros da história, e mesmo em outras áreas das ciências, nas quais os pesquisadores venham a utilizar-se desta fonte plástica como instrumento de apoio à pesquisa e de conhecimento visual do passado. Kossoy salienta que as duas distintas vertentes de investigações têm em comum a utilização dos "próprios documentos fotográficos" como fontes básicas para a pesquisa. Neste sentido, entrecruzam-se respeitando, obviamente, os objetos específicos de investigação de cada uma das vertentes.

O emprego da fotografia para a construção do conhecimento histórico é também um dos objetos de pesquisa da historiadora Ana Maria Mauad, em um de seus artigos denominado "Através da Imagem - 1996", 13 no qual questiona a relação da história à fotografia. A autora aponta dois caminhos para discutir a questão. O primeiro seria tomar a direção da história $d a$ fotografia, salientando que, recentemente, além de inventariar os processos de evolução das técnicas, tem-se buscado compreender a inserção social da imagem. Para tanto, a autora discute o que se convencionou chamar de "circuito social da fotografia", 14 observando que este compreende todo o processo de produção, circulação e consumo das fotografias. O segundo caminho, sinalizado por Mauad, é no sentido de compreender o lugar da fotografia na história.

13 MAUAD, Ana Maria. Através da Imagem: Fotografia e história - Interfaces. In: Revista Tempo, Rio de Janeiro, Relume-Dumará, Universidade Federal Fluminense, Departamento de História, v. 1. p. 73-98, 1996.

14 Para maiores detalhes sobre o circuito social da fotografia pode-se consultar a obra organizada por: FABRIS, Annateresa. Fotografia (usos e funções no século XIX). São Paulo: EDUSP, 1988. 
Procurando compreender o lugar da fotografia na história, a mesma autora, juntamente com Ciro Flamarion Cardoso ${ }^{15}$ observam que a ampliação da noção de documento abrange novos textos, tais como a pintura, o cinema, a fotografia e outros. Estes novos documentos seriam também plausíveis de leitura por parte do historiador. No caso da fotografia, especificamente, a opção da autora seria pela leitura via semiótica, entendendo que a imagem transmite uma mensagem, que pode ser interpretada e conhecidos alguns de seus significados.

A interpretação da imagem fotográfica é uma preocupação presente na obra de Miriam Moreira Leite. ${ }^{16}$ A autora identifica duas correntes historiográficas: uma considera que o documento fala e que a imagem fotográfica transmite clara e diretamente informações; a outra corrente concebe as imagens fotográficas enquanto representações que aguardam um leitor para decifrá-las. Neste sentido, a autora observa que a bibliografia a respeito da interpretação da fotografia não é extensa e que muitos trabalhos se detêm na história da técnica, na biografia dos fotógrafos e na multiplicação da arte fotográfica. Raros são os estudos do significado e do conteúdo cultural da imagem. Por fim, a autora salienta que é preciso um estudo comparativo de sistemas de significados, das mediações entre a realidade que se quer compreender e da imagem dessa realidade.

Os trabalhos recentes que utilizam a fotografia como documento para a construção do conhecimento, principalmente no caso brasileiro, procuram manter uma certa diferença entre a história da fotografia ${ }^{17}$ e a história pela fotografia. Algumas aproximações visam à inserção do documento em um contexto específico, construído pelo conjunto das representações visuais, ou seja, uma certa noção de contexto iconográfico, que compreende todos os elementos estéticos sobre a fotografia em um determinado momento. Salientando que este contexto iconográfico insere-se no contexto histórico, e que tal diferenciação entre a história da fotografia e a história pela fotografia, é basicamente uma questão de

15 CARDOSO, Ciro Flamarion; MAUAD, Ana Maria. História e imagem: os exemplos da fotografia e do cinema. In: CARDOSO, Ciro; VAINFAS, Ronaldo. Dominios da história. Rio de Janeiro: Campus, 1997.

16 LEITE, Miriam Moreira. Retratos de família: leitura da fotografia histórica. São Paulo: EDUSP, 1993.

17 Observa-se que existem algumas obras sobre história da fotografia, independentes da pretensão de se fazer história pela fotografia. Por exemplo: VASQUEZ, Pedro Karp. A fotografia no Império. Rio de Janeiro: Jorge Zahar, 2002. FREYRE, Gilberto et al. O retrato brasileiro. Rio de Janeiro: FUNARTE, 1983. 
abordagem, que permite analisar elementos pertencentes especificamente à imagem fotográfica.

Entende-se, portanto, que a fotografia se insere em um determinado momento da história e serve como fonte para a sua reconstituição. Neste sentido, About e Chéroux ${ }^{18}$ concebem que, teoricamente a história poderá cruzar a fotografia, pois esta é constitutivamente histórica, dando uma forma tangível aos fatos e registra elementos do passado, isto é, um ar, um gesto, um olhar, uma tensão, que os outros documentos dificilmente contemplam. $\mathrm{Na}$ perspectiva de que a história pode cruzar a fotografia, é necessária a percepção deste duplo sentido de orientações da história da fotografia, enquanto suporte para a história pela fotografia. Essas, antes de tudo, são vertentes complementares que recorrem à fotografia como fonte visual e estabelecem especificidades em termos de problematização do objeto de estudo.

\section{Por uma história social da fotografia}

As atuais discussões e produções em história social da fotografia ultrapassam os limites de uma história da fotografia que visava apenas o conhecimento das técnicas, a importância de alguns fotógrafos, os artefatos da imagem e outras observações muito específicas sobre a mesma. Pode-se contar com uma série de obras de historiadores que investigam a fotografia inserida socialmente, situada em seu contexto histórico de pertencimento. Autores franceses como Michel Frizot, André Gunthert, Michel Pouvert, Georges Didi-Huberman, Clément Chéroux, André Rouillé, dentre outros, procuram investigar a fotografia como um produto social, considerando as mediações entre a imagem e a sociedade e a maneira pela qual a fotografia retrata a sociedade e as relações sociais.

A configuração de uma história social da fotografia perpassa pela compreensão de que, em primeiro lugar, a fotografia é um produto social e a sua construção revela as demandas de diferentes grupos sociais. Estes mesmos grupos podem utilizar-se da fotografia para divulgar e legitimar o seu poder em um determinado momento e como forma de divulgação e de imposição de representações sociais, sendo estas matrizes para as práticas sociais, que podem interferir na construção de modelos ideais de comporta-

18 ABOUT, Ilsen; CHÉROUX, Clément. L'histoire par la photographie. In: Études Photographiques, Paris, Société Française de Photographie, n. 10, 2001. 
mentos a serem seguidos pelos demais grupos de uma sociedade. Esta forma impositiva de legitimação das representações, por intermédio das fotografias, serve também como um meio importante para a construção da identidade, tanto individual quanto coletiva.

O historiador Michel Frizot, ${ }^{19}$ a partir de reflexões realizadas em várias obras, delineia a história social da fotografia, separandoa da história da arte. $\mathrm{O}$ autor pondera que a história da arte foi construída com nomes de grandes artistas, definindo tendências quase generalizadoras. No caso da história da fotografia, de acordo com ele, é preciso voltar a pesquisar informações mais consistentes a respeito da vida dos fotógrafos, recolher as imagens não apenas como uma vaga colocação das imagens no mundo e procurar saber as motivações e as intenções presentes no momento da produção das imagens.

Frizot entende a fotografia como um documento e, especificamente, um documento histórico, pois pode ser datada e constituída com as particularidades do instante de tomada; neste sentido, representa um fragmento da história geral e um índice provante. $\mathrm{O}$ autor observa que, para alguns, a fotografia é uma visão objetiva do mundo, uma maneira de inventariar, enquanto para outros, é uma visão totalmente subjetiva, e o fotógrafo é visto como um artista que compõe a fotografia com a realidade e desta se apropria, a fim de melhor mostrar a si próprio. Além disso, Frizot enfatiza que é preciso desacreditar esta dicotomia documento/arte, para melhor insistir a respeito da variedade das práticas e sobre os usos intencionais que sustentam a produção de fotografias.

O mesmo autor acredita que, para melhor entender a história social da fotografia, é preciso, num primeiro momento, reconstruir a história dos fotógrafos, situando a obra destes em seu tempo, não apenas enquanto continuidade, mas com uma certa arqueologia de toda a produção, a tecnologia empregada e a linguagem fotográfica de cada época. É preciso também perceber as implicações e as ações dos fotógrafos em um determinado momento, no sentido de observar como a sociedade, em sua totalidade, é implicada pela fotografia e como os fotógrafos selecionam ou exacerbam as modalidades de ser dos atores sociais ou das situações fotografadas.

Frizot considera que a análise da imagem fotográfica depende de uma outra mediação, estabelecida individualmente e defini-

19 FRIZOT, Michel (Dir.). Nouvelle Histoire de la Photographie. Paris: Adan Biro / Larousse, 2001. _ . FRIZOT, Michel (Org.). Histoire de voir. Paris: Nathan/Centre national de la photo, 1989. — . Du bom usage de la photographie. Paris: Centre national de la photo, 1897. 
da por cada autor um ponto de vista que é histórico, confrontando o olhar do fotógrafo e do espectador em suas diferentes variações temporais e espaciais. Neste sentido, adentrando no campo de análise das representações visuais, as quais podem apresentar diferentes significados ao longo de sua historicidade.

\section{As imagens fotográficas e as representações visuais}

A fotografia entendida como representação visual, também é discutida por autores que trabalham com a semiótica, os quais a consideram como um signo. Dentre esse autores estão os franceses: Philippe Dubois, Denis Roche, Henri Vanlier, ${ }^{20}$ Jean-Marie Schaeffer $^{21} \mathrm{e}$, no Brasil essa corrente já possui vários adeptos. ${ }^{22}$ Estes autores utilizam-se da semiótica para o entendimento da relação existente entre a representação visual e o objeto ou referente que deu origem à representação. Os estudos avançados em semiótica permitem criar instrumentos metodológicos para a leitura dos elementos que compõem a imagem, permitindo uma análise detalhada do interior da mesma.

A fotografia como uma representação visual é defendida por Philippe Dubois, ${ }^{23}$ a partir da análise dos diferentes discursos que a caracterizam. A primeira classificação dos discursos considerava a fotografia como espelho do real, ${ }^{24}$ sendo esta uma ilusão da realidade, um duplo. O referido autor observa que os discursos do século XIX concebiam a fotografia como uma imagem formada pela máquina sem a interferência do homem, desprovida de subjetividade e de intencionalidade do produtor. Ainda observa que os mesmos discursos elucidavam que o efeito da realidade ligado à imagem fotográfica foi, a princípio, atribuído à semelhança entre a foto e seu referente. A fotografia foi percebida como um analogon, objetivo do real. Estes discursos também serviam para justificar as diferenças ente a fotografia e a obra de arte, a primeira seria o simples registro da máquina e a segunda produzida pelo talento manual do artista.

20 VANLIER, Henri. Philosophie de la photographie. In: Les Cahiers de la Photographie, Paris, ACCP, edição especial, 1983.

21 SHAEFFER, Jean-Marie. A imagem precária (sobre o dispositivo fotográfico). São Paulo: Papirus, 1996.

22 Para uma consulta sobre essa tendência no Brasil, tem-se a obra de: SAMAIN, Etienne (Org.).O fotográfico. São Paulo: Hucitec, 1988.

23 DUBOIS, Philippe. O ato fotográfico e outros ensaios. Campinas: Papirus, 1994.

24 Idem, ibidem, p. 27. 
A segunda classificação dos discursos, observados por Dubois, considera a fotografia como transformação do real, ${ }^{25}$ reunindo, neste grupo, todos os trabalhos que analisam o discurso do código e da desconstrução, formulados no século XX. O mesmo autor afirma que estes trabalhos criticam o discurso da mímese e da transparência da fotografia, considerando-a como eminentemente codificada, sob os diversos pontos de vista, quais sejam: técnico, cultural, sociológico, estético. Situam-se nessa tendência autores como John Collier, ${ }^{26}$ Pierre Bourdieu, ${ }^{27}$ Rudolf Arnhein e outros.

A terceira classificação elaborada por Dubois considera $a$ fotografia como um traço do real, ${ }^{28}$ destacando o discurso do índice e da referência. O referido autor afirma que se deve prosseguir na análise da imagem para avançar além da simples denúncia do efeito do real. Neste sentido, interrogando-a de acordo com os outros termos da própria ontologia da imagem fotográfica. Considera a fotografia como procedente da ordem do índice (representação por contigüidade física do signo com seu referente), ${ }^{29}$ cuja concepção distingue-se claramente das duas precedentes, principalmente pelo fato de perceber que a imagem fotográfica é dotada de um valor todo singular, visto ser determinada por seu referente, e por assim dizer, um traço do real. A fotografia como índice pode ser traduzida como uma representação visual de seu referente, ${ }^{30}$ concebido como uma construção em um determinado tempo e espaço.

As possíveis aproximações entre os autores que trabalham com história social da fotografia e semiótica da imagem podem ser percebidas pelo consenso de que ela é essencialmente uma representação visual. O primeiro grupo tem uma preocupação mais liga-

25 Idem, ibidem, p. 36.

26 COLLIER, John. Antropologia visual: a fotografia como método de pesquisa. São Paulo: EDUSP, 1973.

27 BOURDIEU. Pierre. Un art moyen - essai sur les usages sociaux de la photographie. Paris: Les Éditions de Minuit, 1965.

28 DUBOIS, Philippe. O ato fotográfico e outros ensaios. Campinas: Papirus, 1994. p. 45.

29 Para a classificação da fotografia como índice, Dubois utiliza-se das formulações sobre signo, baseadas na obra de Charles S. Peirce.

30 A noção de referente utilizado por Philippe Dubois é tomada da obra de BARTHES, Roland. A câmara clara. Lisboa: Edições 70, 1980. Na página 109 de seu livro, Barthes define referente como: "O referente da fotografia não é o mesmo dos outros sistemas de representação. Chamo de referente fotográfico não a coisa facultativamente real para que remete uma imagem ou um signo, mas a coisa necessariamente real que foi colocada diante da objetiva sem a qual não haveria fotografia. A pintura, essa pode simular a realidade sem a ter visto. $\mathrm{O}$ discurso combina signos que têm certamente referentes, mas esses referentes podem ser e na maioria das vezes são quimeras. Ao contrário dessas imitações, na fotografia não posso negar que a ciosa esteve lá, há uma dupla composição conjunta de realidade e passado". 
da à historicidade da imagem e as formas de construção da visualidade da sociedade e, o segundo grupo, com ênfase maior para o entendimento da ontologia da imagem, classificando-a como um signo. Procuram, esse segundo grupo também entender os significados das mensagens impressas nas imagens e como se constitui o universo simbólico de uma determinada sociedade. Todavia alguns autores, dentre eles Rouillé, ${ }^{31}$ fazem uma crítica às classificações daqueles que trabalham com semiótica aplicada à fotografia, principalmente com relação à noção de ontologia. Rouillé afirma que não se pode substituir a história pela ontologia, pois é na história que se busca a contextualização dos fenômenos para distinguir a pluralidade das práticas, das imagens e das obras.

Entende-se que para trabalhar com representações visuais na historiografia, uma das possibilidades seria a aproximação com a história cultural, pois esta se constitui em uma tendência privilegiada para os estudos sobre representações. Assim, seguem-se algumas formulações discutidas por Chartier, ${ }^{32}$ que se propõe a discutir a importância da representação para o entendimento do universo cultural. O seu artigo (O mundo como representação - 1989) representou um verdadeiro manifesto para os historiadores que trabalham com cultura. Para Chartier, ${ }^{33}$ o conceito de representação pode ter dois sentidos quase opostos. Primeiro, a representação como substituição por uma forma de representar a ausência. Segundo, a representação como exibição, demonstração, adição, a representação e o representado, exibição de poder e de identidade.

A história cultural trabalhada por Roger Chartier ${ }^{34}$ é uma modalidade que procura entender a produção de sentido das pa-

31 ROUILLÉ, André. Uma image sens qualités? In: La Recherche Photographique, Paris, Paris Audiovisuel, n. 18, 1995.

32 CHARTIER, Roger. Le monde comme représentation. Paris: Annales ESC, 1989. Este texto é considerado um retorno a Marcel Mauss e a Emile Durkheim, os quais introduziram a noção de representação coletiva no vocabulário sociológico no começo do século XX.

33 Chartier discute a noção de representação em várias obras dentre elas o já citado artigo (O mundo como representação). Além disso, podem-se consultar outras, tais como: CHARTIER, Roger. A história cultural - entre práticas e representações.Lisboa: Difel, 1990. CHARTIER, Roger. A história hoje: dúvidas, desafios, propostas. In: Estudos Históricos, Rio de Janeiro, v. 7, n. 13, 1994. Outro importante artigo que discute as relações entre história e representações de autoria de Michel Volvelle (Histoire et représentations) In: BORBALAN-RUANO, Jean-Claude (Org.). L'histoire aujoud'hui. Paris: Éditions Sciences Humaines, 1999, p. 45-49.

34 Na entrevista de Chartier para Martine Fournier, o autor sintetiza sua posição afirmando que a importância da história cultural é dada pelo estudo das descontinuidades e das diferenças. In: BORBALAN-RUANO, Jean-Claude (Org.). L'histoire aujourd 'hui. Paris: Éditions Sciences Humaines, 1999, p. 17. 
lavras, das imagens e dos símbolos e busca a reconstrução das práticas culturais em termos de recepção, de invenção e de lutas de representações. Trabalha também com as diferentes formas de apropriação de discursos, de textos (verbais e não-verbais) e da produção do sentido, sendo este diferenciado pelas posições que os atores ocupam socialmente. Nesta perspectiva, mostram algumas dependências da vida cultural, que aparecem nas diferentes formas de apropriação, mediadas pela representação.

Os estudos mais significativos em história cultural procuram evidenciar a relação da cultura com o universo social. ${ }^{35}$ Neste semtido, a cultura não é uma instância separada deste universo, mas participa das relações sociais existentes em uma determinada sociedade. A cultura ${ }^{36}$ é sempre uma construção social e constituída pelo conjunto de práticas e de valores que podem ser passados por várias gerações e é perpassada pelas variações que dependem das temporalidades e dos grupos sociais que a produzem. A cultura não se transmite de uma forma imutável e é, portanto, uma produção histórica. ${ }^{37}$

\section{A construção da cultura fotográfica}

A cultura fotográfica pode ser entendida como uma das modalidades da cultura singularizada por constituir uma prática específica de produção, de circulação e de consumo da imagem e é, também, um dos possíveis meios que permite a visualização e o entendimento de várias práticas sócio-culturais, que compõe o universo dos atores sociais. A nível historiográfico, essa dimensão da cultura pode ser trabalhada no campo da história cultural, pois não se limita tão somente ao entendimento das representações

35 Importante discussão sobre as relações entre cultura e universo social está presente na obra de: BOUZA, Fernando. Uma historia cultural do siglo de oro. Madrid: Marcial Pons, 2001.

36 Para uma discussão sociológica sobre cultura ver a obra de: WILLIAMS, Raymond. Cultura. Rio de Janeiro: Paz e Terra, 1992. Uma visão mais antropológica na obra de: GEERTZ, Clifford. A interpretação das culturas. Rio de Janeiro: Guanabara, 1989. Uma síntese sobre a noção do termo cultura e sua historicidade pode ser vista na obra de: CUCHE, Denis. A noção de cultura nas ciências sociais. Bauru (SP): EDUSC, 1999.

37 A cultura como produção histórica é um debate iniciado em meados do século XX. Balandier comenta: "[...] se a cultura não é um dado, uma herança que se transmite imutável de geração em geração, é porque ela é uma produção histórica, isto é, é uma construção que se inscreve na história das relações dos grupos sociais entre si.”. Apud. CUCHE, Denis. A noção de cultura nas ciências sociais. Bauru, SP: EDUSC, 1999. p. 128. 
visuais, mas deve-se estender a análise a todo o processo de produção desta prática específica da cultura.

A noção de cultura fotográfica ainda é uma discussão muito recente no Brasil, tanto entre os historiadores quanto entre os demais cientistas sociais que trabalham com imagens fotográficas. Neste sentido, é um desafio propor um estudo específico sobre esta noção, ao mesmo tempo, que se espera contribuir para o entendimento das múltiplas formas de expressão da cultura. As primeiras discussões, iniciadas por Maria Inez Turazzi ${ }^{38}$ em seu texto com a denominação (Uma cultura fotográfica - 1998) afirma que a cultura fotográfica é uma das formas de cultura, evidenciada pelo argumento de que a fotografia foi e ainda é um recurso visual importante e eficaz para formação do sentimento de identidade, tanto individual quanto coletiva. Igualmente, é também um dos meios que materializa a "visão de si, para si e para o outro" e uma visão do outro e de nossas diferenças. Nas constatações da mesma autora, a cultura fotográfica é uma das formas de cultura ${ }^{39}$ inserida em uma dimensão maior do universo cultural.

A mesma autora entende que a cultura fotográfica constituise em diferentes dimensões, possuindo um grau de complexidade. A começar pelos produtores da fotografia, Turazzi afirma que a mesma cultura refere-se a toda bagagem profissional dos fotógrafos, podendo incluir os equipamentos, as escolhas formais e estéticas e as diferentes tecnologias utilizadas na produção da imagem. Neste momento das argumentações, pode-se aproximá-la da concepção de Michel Frizot, que evidência a importância de se fazer uma certa arqueologia da obra dos fotógrafos, situando-a em uma determinada temporalidade.

A cultura fotográfica também revela a importância da fotografia como uma prática social, incorporada há mais de um século e meio ao modo pelo qual se representa o mundo e a nós mesmos. Salienta-se que esta cultura tornou-se parte importante da experiência visíva moderna. A mesma autora ainda observa que uma cultura fotográfica se expressa nos usos e nas funções da fotografia, na construção das representações imaginárias associadas ao conteúdo ou à utilização dessas imagens em uma sociedade.

38 TURAZZI, Maria Inez. Uma cultura fotográfica. In: Revista do Patrimônio Histórico e Artístico Nacional, s.l., n. 27, 1998.

39 Importante observar que a denominação uma das formas da cultura é, ao mesmo tempo, uma possibilidade de entender as variedades culturais presentes em toda a sociedade. Para maior esclarecimento ver a obra de: PETER, Burke. Variedades da história cultural. Rio de Janeiro: Civilização Brasileira, 2000. 
A complexidade da cultura fotográfica está na diversidade dos atores sociais que a produzem. Sobre isso, Turazzi observa que essa forma de cultura não pode ser compreendida apenas pelas figuras de fotógrafos importantes, mas por profissionais de diferentes espaços e temporalidades. Esta cultura não se restringe às imagens de lugares consagrados, tais como, arquivos, museus, jornais ou grandes coleções privadas. A cultura fotográfica de uma sociedade forma-se pela incorporação da fotografia em todos os domínios da vida social, ou seja, no artesanato popular, nas crenças religiosas e políticas, nas sociabilidades familiares, urbanas e outras, enfim, comporta toda a produção fotográfica de uma sociedade.

O estudo de uma cultura fotográfica é uma proposta que visa não apenas a identificação e o conhecimento dos fotógrafos que atuaram em um determinado espaço ou a sua grande produção de imagens fotográficas, mas, fundamentalmente, procura entender como esta prática fotográfica foi desenvolvida, produzindo-se imagens que representam de certa forma a materialização da cultura e, ao mesmo tempo, como as fotografias são utilizadas para testemunhar as diversas formas de vivência. Trabalha-se com a proposição de que a fotografia é elemento importante que participa do processo de formação da identidade, ${ }^{40}$ tanto individual quanto coletiva dos grupos fotografados.

Os usos das imagens pelos diferentes grupos sociais também se traduzem nas formas como os mesmos afirmam o poder na sociedade, pois as formas de representação impressas nas fotografias intencionam o desejo de mostrar-se de uma maneira considerada ideal para os distintos contextos. As intenções de construção da visualização da mesma sociedade é um meio de mostrar-se para si e para os outros, revelando não somente o que se havia conquistado, mas a organização das diferentes sociedades em suas formas produtivas ou mesmo nos modelos idealizados de representação, os quais podem ser apropriados de outros contextos, tanto pelos fotógrafos quanto pelos fotografados. ${ }^{41}$

A cultura fotográfica é uma modalidade da cultura que participa na construção da memória, tanto individual quanto coletiva. Neste sentido, a fotografia apresenta-se como elemento privilegia-

40 Toma-se como referência a noção de identidade formulada por Stuart Hall, In: HALL, Stuart. A identidade cultural na pós-modernidade. Rio de Janeiro: DP\&A, 2001.

41 Para maiores detalhes sobre a cultura fotográfica pode-se consultar a minha tese de doutoramento: CANABARRO, Ivo dos Santos. A construção da cultura fotográfica no sul do Brasil: imagens de uma sociedade de imigração. Universidade Federal Fluminense (tese de doutorado), Niterói, RJ, 2004. 
do para a materialização da memória, pois segundo Jacques Le Goff, ${ }^{42}$ a fotografia possibilita a multiplicação e a democratização da memória, dando precisão e verdade que as demais fontes não conseguiriam. Assim, toda a produção imagética constitui um patrimônio cultural que permite conhecer as singularidades dos grupos retratados e da própria sociedade.

42 LE GOFF, Jacques. História e memória. Campinas: Unicamp, 1996. 